\title{
3GR technique to enhance run of the road analysis
}

\author{
M. Abdalla \\ G.I.S, Toronto, Canada \\ Ryerson University, Canada \\ Lecture University of Bahrain, Bahrain \\ MRICS, UK \\ P. Eng., Ontario, Canada
}

\begin{abstract}
Both run of the road and head-on crashes are 1.5 to 4 times more likely to occur on curves than on tangents. On the other hand, Canada has over one million kilometres of roads, compared with the UK's $372,000 \mathrm{~km}$ and Sweden's 138,000 $\mathrm{km}$. This means that drivers face much longer travel distances and a wider variety of road conditions. This encourages us and all specialists that work in road safety to use all possible data and to implement new techniques to save more lives and reduce the number of collisions and their economic impact. In this paper, the $3 \mathrm{GR}$ technique has been implemented to enhance run of the road (ROR) analysis. The 3GR technique depends on the integration of a geospatial Information system (GIS), a global position system (GPS), a Global System for Mobile communication GSM and Remote Sensing for road safety. This new technique will enhance the two main parts of road safety studies. First, in Network Screening, the new technique will help the road safety analysts to identify more accurately the sites with higher-than-expected accident frequencies and sites whose accident frequencies are not higher than expected, but which nevertheless experience sufficient numbers of accidents that may potentially be improved in a cost-effective manner. Second, it will help the road analysts in the Diagnosis stage to identify and focus on the real problems at specific sites. As a result of our research, we present the advantages of this technique and discuss the future steps.
\end{abstract}

Keywords: remote sensing, GIS, GPS, GSM, road-safety, run of the road. 


\section{Introduction}

Every year more than 1.17 million people die in road crashes around the world. It has been estimated that at least 6 million more will die and 60 million will be injured during the next 10 years in developing countries unless urgent action is taken. Road crashes cost approximately 1 to $3 \%$ of a country's annual Gross National Product (GNP) [1].

The annual cost of road collisions in Great Britain (including medical, police, insurance, lost output, damage to property and an allowance for pain, grief and suffering) is huge. Road Accidents Great Britain 2001 estimates the cost of all road accidents as $£ 17,418$ million with $£ 12,530$ million of that due to personal injury accidents.

\subsection{Road safety}

Road safety is not an easy target to get. A lot of work should be done to improve the road safety. Road safety is not the responsibility of the engineers only but it is the responsibility of all the community.

To reach that target we have to:

- Identify road-crashing problem

- $\quad$ Clarify the Economic Perspective on Traffic Safety.

- Develop a Road Safety Plan.

- $\quad$ The Institutional Responsibility of Road Safety should work together.

- Monitor our road network

- Evaluate the treatment decisions.

- Design flexible data System and create a new way to collect and fill the gap in our data

- Use different analysis methods to reach the right decision.

- $\quad$ Finance Road Safety and put priority on the treatment sites.

- Exam and re-evaluate designing roads to Improve Road Safety (Safety Engineering).

- $\quad$ Road Safety Audits

- Improve Children's Traffic Education program.

- Increase Publicity Programs.

- $\quad$ Update and evaluate driver training and testing.

- Traffic Law and Enforcement.

- Improve Vehicle Safety Standards.

- Emergency Medical Services.

\subsection{Run of the road}

Both run of the road (ROR) and head-on crashes are 1.5 to 4 times more likely to occur on curves than on tangents [2]. Zegeer et al. [3] found that ROR crashes accounted for approximately $57 \%$ of the total crashes on a sample of over 11,000 curves on two-lane rural roads. While many of the other strategies in this section (e.g., rumble strips, shoulder treatments, wider clear zones, and skidresistant pavement) would have equal or greater effectiveness on curves, crash 
reductions on curves can also be realized through tailored programs. Specifically, flattening curves (i.e., increasing the curve radius on two-lane rural roadways) has been found by Zegeer et al. to result in total curve crash reductions of up to $80 \%$ (i.e., flattening a 30-degree curve to 5 degrees). Thus, this strategy has been "proven" to reduce crashes. Given the size of these potential reductions, an agency should clearly consider this as a treatment alternative for locations with significant ROR problems if right-of-way and funding are available.

\subsection{Road safety research}

We can summarize the road safety research from a road safety analysts' point of view to the following main branches:

- Network screening

- Sites diagnose

- Decision evaluation.

\subsection{Network screening}

The main aim of network screening is observing the accident and analysing the data. Meanly, the data are subject to regression to the mean, because high shortterm accident frequencies are likely to decrease and low short-term accident frequencies are likely to increase as a matter of course, even if no improvements are made.

The relationship between accident frequency and traffic volume is known to be non-linear. As a result of network screening we can know:

- Which sites have experienced the most accidents, but not which sites could benefit most from a safety improvement.

- $\quad$ Sites with higher-than-expected accident frequencies.

- And Sites whose accident frequencies are not higher than expected, nevertheless experience sufficient numbers of accidents that may potentially be improved in a cost-effective manner.

\subsection{Diagnosis the problems}

Network screening can highlight for us the sites which have safety problems. The next step is to study those sites and diagnose the problem for the specific sites. Really, it is one of the most important steps to improve the road safety. It needs one to collect more specific data for the site, cover any gap in the existing data, site visit, site investigation and a lot of experience.

\section{The data}

Traditional methods for manually collecting detailed information on street segments in the field are costly and time-consuming, and agencies should consider all possible information resources and develop new techniques that can reduce the cost and time involved in database development [4]. This paper presents an inexpensive and reliable approach for identifying missing and 
conflicting data in network screening databases. The approach is based on integrating GIS and remote sensing with network screening and collision databases [5].

The following sections describe the components of the integrated system and the proposed methodology for resolving missing or conflicting segment data. In this paper we focus on diameters of existing curves and bearing of straight lines of road segments. The capabilities of the methodology in resolving other database inconsistencies are then described, followed by the concluding remarks.

\subsection{Integrated system}

The integrated system includes four components: single line road network, network screening database, collision database, and digital orthophotos.

\subsubsection{Single line road network}

The Single Line Road Network (SLRN), which played a key role in the proposed methodology, is a representation of the road network centerline of the region in GIS format. It contains more than 15,000 segment records. The segment length varies from less than $15 \mathrm{~m}$ to more than $7 \mathrm{~km}$. The SLRN contained such features as address range and street name, along with another 25 different attributes for all segments of the road network. The user can find the attribute of a selected segment (Selection by Location) or segments that have specific attributes (Selection by Attributes). The identification (ID) numbers of the segments in the SLRN were modified to be compatible with those of the databases.

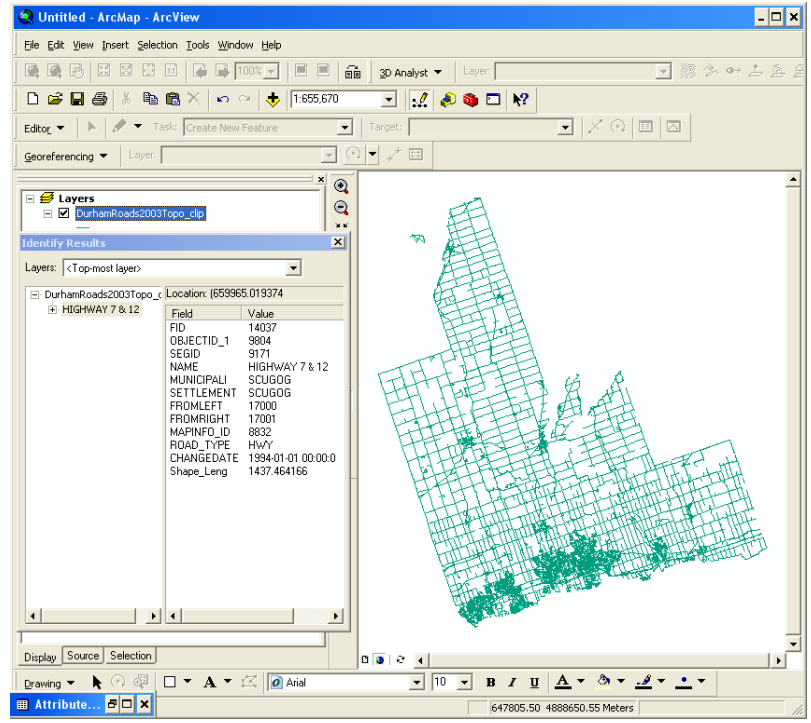

Figure 1: $\quad$ Representation of SLRN of the study region in ArcView. 


\subsubsection{Network screening database}

The network screening database consisted of 42 different electronic files. These files contain all the data available for the regional road network. The files were subdivided into two groups: the network screening database and the collisions database (described later). The network-screening database contained all road records except those that have direct relation with collisions.

The network-screening database included the following data groups: road type, road jurisdiction, lighting condition, road alignment, road surface, road pavement markings, road condition, radius, degree of the curve and traffic control. Sample contents of the items in each category are shown in Table 1. The network-screening database includes other types of data, such as annual average daily traffic and road pavement markings. In this study, separate tables with information related to segments and segment lighting condition were linked using ArcView.

\subsubsection{Collision database}

The collision database (70,871 records) includes a 10 -year period of collisions within the Region. Table 2 shows example contents of the collision database. The database uses data obtained from three electronic files. The first file contains collision data, such as collision ID numbers, day of week, light condition, and number of vehicles, persons and pedestrians involved. The second file contains collision location data, such as collision location $(\mathrm{N}$ and $\mathrm{E}$ coordinates in Universal Transverse Mercator format), impact type, municipality, and road jurisdiction. The third file contains collision classification.

To create the collision database, the three preceding files were linked using ArcView. The software allows the user to link data tables (files) using one of two operations: joining or relating. The joining operation appends the fields of one table to those of another through an attribute of a field common to both tables. This operation is usually used to attach more attributes to the attribute table of a geographic layer. The relating operation establishes a temporary connection between records of two tables using a field common to both tables. In this study, the joining operation was used to link all the three collision data files based on collision the ID field.

\subsubsection{Digital orthophotos}

Digital orthophotos with a special $0.2-\mathrm{m}$ resolution were used in this study to extract the segments type if the analysis of the integrated system identifies missing or conflicting data. The orthophotos covered a region characterized by vibrant urban and rural communities, and thriving commercial and industrial sectors. The region is located in the economic centre of Ontario, near the City of Toronto. The region encompasses an area of over 2,500 square kilometres, 60 arterial roads with a total length of $760 \mathrm{~km}$. The routes selected for the study have a total length of $140 \mathrm{~km}$. The grey values of the pixels, which cover this area, required enormous storage space. To resolve this issue, the images were divided into small windows that covered the targeted segments. The small windows were then used in the analysis. 
Table 1: $\quad$ Sample contents of road network screening database.

\begin{tabular}{|l|l|l|l|}
\hline \multicolumn{1}{|c|}{$\begin{array}{c}\text { Road } \\
\text { Element }\end{array}$} & \multicolumn{1}{|c|}{ Example Items } & Road Element & Example Items \\
\hline Road Type & $\begin{array}{l}\text { Undivided - one-way } \\
\text { Undivided - two-way } \\
\text { Divided, no barrier } \\
\text { Collector lane }\end{array}$ & $\begin{array}{l}\text { Road } \\
\text { Surface }\end{array}$ & $\begin{array}{l}\text { Asphalt } \\
\text { Gravel } \\
\text { Concrete } \\
\text { Earth }\end{array}$ \\
\hline $\begin{array}{l}\text { Road } \\
\text { Jurisdiction }\end{array}$ & $\begin{array}{l}\text { Municipal } \\
\text { Provincial highway } \\
\text { County or district } \\
\text { Private property }\end{array}$ & $\begin{array}{l}\text { Road Pavement } \\
\text { Markings }\end{array}$ & $\begin{array}{l}\text { Exist } \\
\text { Non-existent } \\
\text { Obscured } \\
\text { Faded }\end{array}$ \\
\hline $\begin{array}{l}\text { Lighting } \\
\text { Condition }\end{array}$ & $\begin{array}{l}\text { Artificial light } \\
\text { No artificial light }\end{array}$ & $\begin{array}{l}\text { Road } \\
\text { Condition }\end{array}$ & $\begin{array}{l}\text { Good } \\
\text { Poor } \\
\text { Under } \\
\text { construction }\end{array}$ \\
\hline $\begin{array}{l}\text { Road } \\
\text { Alignment }\end{array}$ & $\begin{array}{l}\text { Straight on level } \\
\text { Straight on hill } \\
\text { Curve on level } \\
\text { Curve on hill }\end{array}$ & Traffic & $\begin{array}{l}\text { Traffic signal } \\
\text { Stop sign } \\
\text { Yield sign } \\
\text { No control }\end{array}$ \\
\hline
\end{tabular}

Table 2: $\quad$ Sample contents of collision database.

\begin{tabular}{|c|c|c|c|}
\hline $\begin{array}{l}\text { Collision } \\
\text { Element }\end{array}$ & Example Items & $\begin{array}{l}\text { Collision } \\
\text { Element }\end{array}$ & $\begin{array}{c}\text { Example } \\
\text { Items }\end{array}$ \\
\hline Collision location & $\begin{array}{l}\text { On Highway: } \\
\text { Non intersection } \\
\text { Intersection related } \\
\text { At intersection } \\
\text { Off Highway }\end{array}$ & $\begin{array}{l}\text { Environment } \\
\text { condition }\end{array}$ & $\begin{array}{l}\text { Clear } \\
\text { Rain } \\
\text { Snow } \\
\text { Strong wind } \\
\text { Fog, mist, } \\
\text { smoke, dust }\end{array}$ \\
\hline $\begin{array}{l}\text { Lighting } \\
\text { condition }\end{array}$ & $\begin{array}{l}\text { Daylight \& } \\
\text { Daylight-artificial } \\
\text { Dawn \& Dawn- } \\
\text { artificial } \\
\text { Dark-artificial } \\
\text { Dark-night-time }\end{array}$ & $\begin{array}{l}\text { Traffic control } \\
\text { condition }\end{array}$ & $\begin{array}{l}\text { Functioning } \\
\text { Not } \\
\text { functioning } \\
\text { Obscured } \\
\text { Missing or } \\
\text { Damaged }\end{array}$ \\
\hline $\begin{array}{l}\text { Collision } \\
\text { classification }\end{array}$ & $\begin{array}{l}\text { Fatal injury } \\
\text { Non-fatal injury } \\
\text { Property damage } \\
\text { only } \\
\text { Non-reportable }\end{array}$ & $\begin{array}{l}\text { Initial impact } \\
\text { type }\end{array}$ & $\begin{array}{l}\text { Approaching } \\
\text { Angle } \\
\text { Rear-end } \\
\text { Turning } \\
\text { movement }\end{array}$ \\
\hline
\end{tabular}




\section{Proposed methodology}

The methodology involves four main tasks (Fig. 2):

(1) Integrating SLRN and network screening database,

(2) Integrating SLRN and collision database,

(3) Checking data matching, and

(4) Identifying road segment type and calculate the radius and degree for the curves.

\subsection{Task 1: integrating SLRN and network screening database}

In this task, ArcView was used to join the network-screening database and the SLRN, and a GIS layer was then created. The layer showed two categories (due to straight line or Curve) of segments: (a) segments that have segment-type records, and (b) segments with missing records. The segments with missing records were marked for investigation in Task 4 . For other segments, a new GIS layer was created and the segments were classified into straight-line segments (Type 1) and curved segments (Type 2).

\subsection{Task 2: integrating SLRN and collision database}

As previously mentioned, three collision files were joined using the collision ID as the common record. In this task, the collision database was imported to the GIS system using the "Add X,Y Data" tool which imports the database as a shape-file. The imported collision database was classified into three categories:

1. Collisions on straight-line roads segment, (corresponding segment is Type 1),

2. Collisions on curved roads, (corresponding segment is Type 2), and

3. Other collisions, where the segment types are unknown.

A new GIS layer was then created for the preceding collision categories. To identify segment type, the "Selected Features within a Distance" tool was used. This tool selects features near or adjacent to other features in the same layer or in a different layer by creating a buffer zone. All features intersecting with the created buffer were selected (Fig. 3). In this study, each SLRN segment was identified and given the same curvature category (straight line /curved) as the closest collision. A new GIS layer for segment type was then created and recorded in ArcView format.

\subsection{Task 3: checking data matching}

The results obtained from Tasks 1 and 2 were compared. If there were no conflicts, the results were stored in the database and marked as confirmed (straight-line segment/curved segments). These segments were also added to the final straight-line/curved GIS layer. In addition, the segments were used to calculate the bearing of straight line, radius and degree for the curved segments. Note that, if a segment is identified in Task 2 as unknown, the matching 
operation is treated as a conflict. If a conflict was found, the segment was marked for further investigation and checking. The proposed system was able to identify and correct $95 \%$ of the conflicting and unknown segments.

\subsection{Task 4: Identifying road-segment type}

This task involves identifying segment type if the data is missing in the network screening database or there is a conflict with the collision database. The segment type is identified manually and the bearing of the straight line or the radius/degree of the curved has been calculated by using optimization methods created by the author. The method involves the following major activities: processing of original orthophotos, using edge detection filter, developing grey matrices, and using optimization technique to calculate the bearing for the straight line and radius/degree for the curved parts.

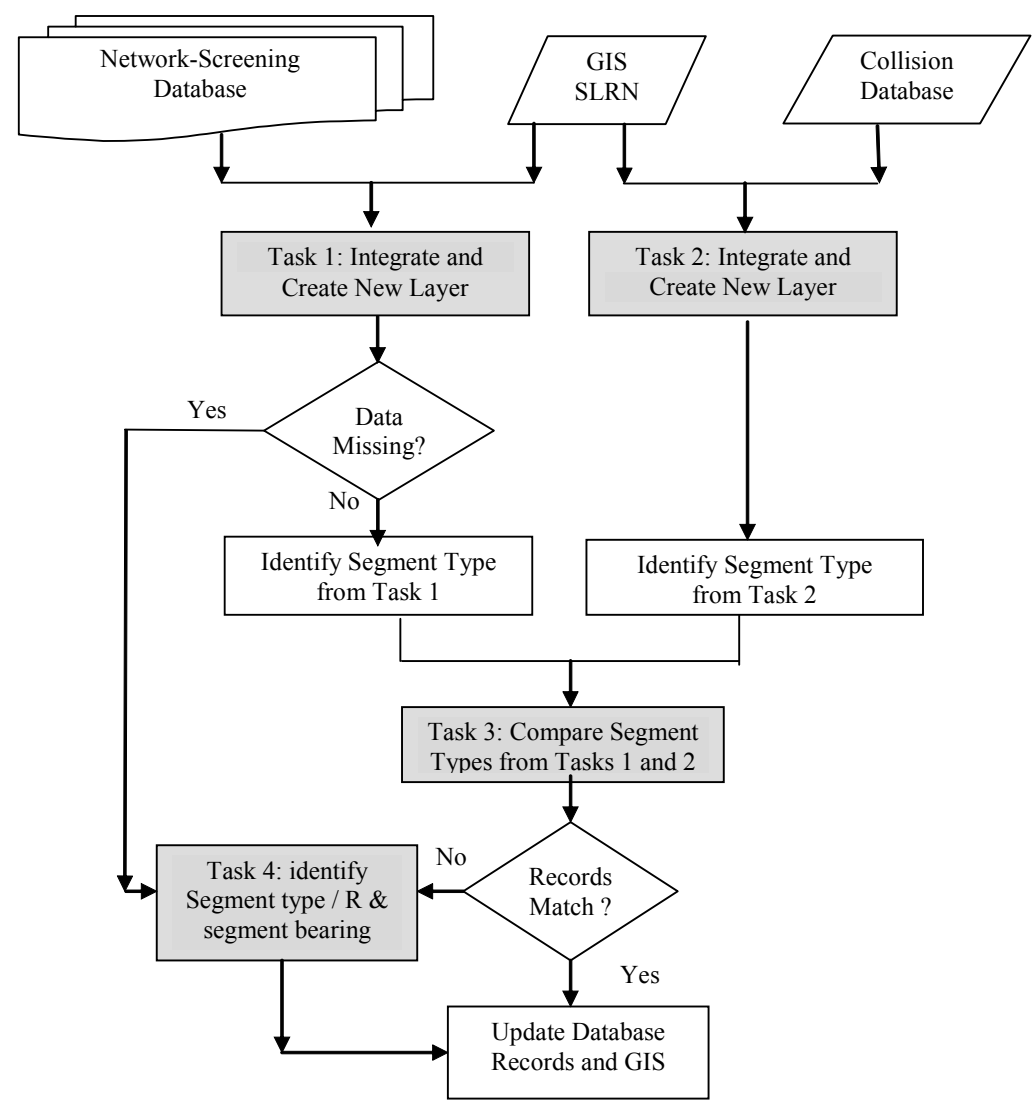

Figure 2: $\quad$ Proposed methodology for enhancing illumination databases. 


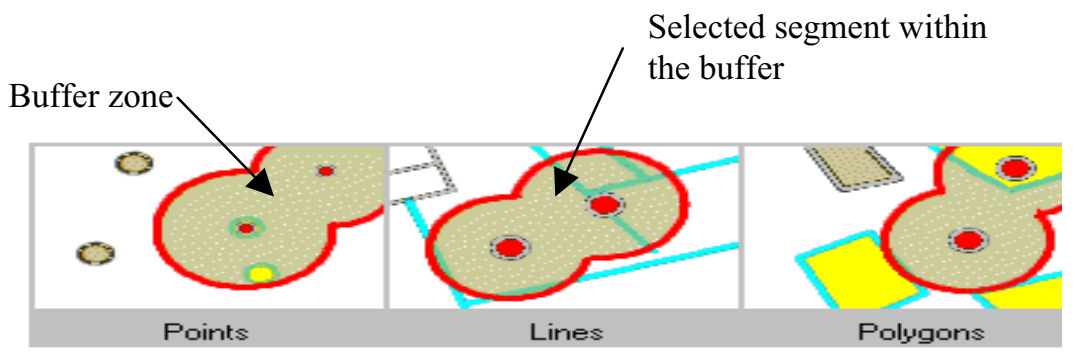

Figure 3: Operation of selected features within a distance tool (ArcView tutorial).

\section{Concluding remarks}

Network-screening databases are used in many transportation applications. Traditional methods of collecting the required database information are expensive and time consuming. The methodology presented in this paper for identifying segment-type is inexpensive and user-friendly. Most of the analysis of the methodology is performed automatically or semi-automatically, and it does not require a strong background in GIS or remote sensing to understand it. In addition, the idea behind the proposed approach is considered unique since it enables not only the analysis of databases (as most other techniques do), but also finding missing data and checking possible inconsistencies in the database.

Improving the quality of network-screening databases can help improve the accuracy of related traffic management and road safety analysis. In particular, identifying radius/degree of the curved segments is an important factor in road safety analysis. While it is not practical to identify the actual radius and degree for all the curvatures segments by normal surveying works, the presented methodology can help identify the radius/degree (for curvatured segments) and the bearing of the straight line segments.

The integration of GIS, orthophotos, and road databases was used in this paper to enhance segment type in network screening databases and check the consistency of the AADT database. With minor modifications, the presented methodology can be used to check other types of data in network screening databases, such as traffic control devices, road classification, and possibly pavement surface.

\section{References}

[1] Canada Safety Council, 2006. Road safety vision 2010. Internet: www.safety-council.org.

[2] Glennon, J. C., T. R. Newman, and J. E. Leisch. Safety and Operational Considerations for Design of Rural Highway Curves, FHWA/RD-86/035. FHWA, U.S. Department of Transportation. 1985. 
[3] Zegeer, C. V., J. R. Stewart, F. M. Council, D. W. Reinfurt, and E. Hamilton. "Safety Effects of Geometric Improvements on Horizontal Curves," Transportation Research Record 1356. Transportation Research Board of the National Academies. 1992.

[4] Canada Safety Council; http://www.safety- council.org/ info/ traffic/ stats2001.html

[5] Abdalla, M and Said M. Easa, (2007), Improving Network Screening Databases By Integrating GIS and Digital Imagery, Canadian journal of Civil Engineering. (under press).

[6] Abdalla, M. and Easa, S.M. 2006. Extracting highway light poles from Orthophotos or satellite imagery. ASCE Journal of Surveying Engineering (under press).

[7] Federal Highway Administration; 2003; "Safety Analyst" http:// www.safetyanalyst.org/ screening.htm

[8] AASHTO. Roadside Design Guide, 3rd Edition. Washington, D.C. (More information can be found at http://www.transportation.org/ publications/ bookstore.nsf/Home?OpenForm). 2002. 